\title{
Black Quarter (BQ) Disease in Cattle and Diagnosis of BQ Septicaemia Based on Gross Lesions and Microscopic Examination
}

\author{
Mahmuda Sultana $^{1}$, Abdul Ahad ${ }^{1 *}$, Paritosh Kumar Biswas ${ }^{1}$, MAshiqur Rahman² ${ }^{2}$ nd Himel Barua ${ }^{1}$ \\ ${ }^{1}$ Department of Microbiology, Chittagong Veterinary \& Animal Sciences University, Khulshi, Chittagong 4202, Bangladesh, ${ }^{2}$ Department of Medicine \\ \& Surgery, Chittagong Veterinary \& Animal Sciences University, Khulshi, Chittagong 4202, Bangladesh
}

[Received 15 May 2007; Accepted 14 June 2008]

\begin{abstract}
Black quarter (BQ) is an acute, infectious disease caused by Clostridium chauvoei - a Gram-positive, anaerobic organism. This disease is characterized by inflammation with gaseous oedema of skeletal muscle and severe toxaemia. This study was done in Upazilla Veterinary Hospital at Raozan in Chittagong from June to August 2006. During the study period, 25 cases of $B Q$ in cattle were found in eight Unions. Among them the highest (32\%) proportion of BQ was found in Raozan Union. Frequency of BQ according to demographic variable was: age incidence of $>12$ month $(60 \%)$, male $(60 \%)$, breed of Red Chittagong $(44 \%)$, body condition score (BCS) of BCS-2 (88\%), and affected body part involving hind quarter muscle (35\%). Death was observed with $73 \%$ cases. In case of animals that were suffered from BQ, septicaemia developed after $12 \mathrm{~h}$ of onset of clinical signs and symptoms. Treatment was ineffective in advanced septicaemic stage. Antibiotic therapy was found to be effective when administered within $12 \mathrm{~h}$ of the clinical symptoms.
\end{abstract}

Keywords: Black quarter, Clostridium chauvoei, Demographic variable, Septicaemia, Antibiotic therapy

\section{Introduction}

Black quarter (synonym: blackleg, quarter ill, quarter evil, symptomatic anthrax, or emphysematous gangrene) is an acute infectious disease of cattle. The disease is infectious and causes severe inflammation of skeletal and cardiac muscle, severe systemic toxicity and, not surprisingly, a high mortality ${ }^{1}$. Black quarter (BQ) is a predominant disease of cattle but traumatic BQ may be seen in other animals ${ }^{2-3}$. In sheep it is almost always secondary to a skin wound. Other species of clostridial bacteria can cause similar symptoms. Black quarter disease is caused by Clostridium chauvoei - a Gram-positive, rod shaped, sporeforming and toxin-producing anaerobe ${ }^{4}$. The spores of the bacterium are very resistant to adverse environmental stress. The spores can withstand high temperature $\left(120^{\circ} \mathrm{C}\right.$ for $\left.10 \mathrm{~min}\right)$ and desiccation and are resistant to disinfectants. The organism can be destroyed by 3\% formalin in $15 \mathrm{~min}$ and by $2 \%$ bichloride of mercury in $10 \mathrm{~min}$. In soil, the spores can persist for a number of years $^{5}$. The organism grows best in media with slightly alkalinity, although it can grow under wide $\mathrm{pH}$ range ${ }^{5}$.

Most cases of black quarter occur in the warm months of the year. Outbreaks can occur following excavation of soil, which can expose and activate latent spores ${ }^{6}$. Also the disease is enzootic in areas with a history of flooding. It is common for a number of animals to be affected within a small time frame. It is assumed that the route of infection in cattle is through the intestinal mucosa following ingestion of the soil borne spores ${ }^{1}$. Black quarter develops when the spores locate in normal skeletal and/or cardiac muscle and then proliferate after localized trauma or anoxia. Toxin is then released resulting in a necrotizing myostitis and systemic toxaemia ${ }^{7}$.

A preliminary diagnosis of black quarter or malignant oedema may be made in the living animal on the basis of clinical signs and the presence of typical muscle swellings ${ }^{6}$. Post-mortem findings in cattle with BQ include dark, discoloured, swollen and rancid muscle upon incision of the affected area ${ }^{1}$. The affected muscle will have excess fluid and bubbles of gas ${ }^{1}$. Body cavities will contain excess fluid and overall decomposition of tissues is rapid. In cardiac myositis there is usually a large accumulation of fluid around the heart with large amounts of fibrin. Quick post-mortem examination and submission of samples to the lab by veterinarian is essential to confirm a diagnosis of $\mathrm{BQ}^{1}$.

The speed with which BQ kills usually makes individual treatment useless. In some cases, however, animals treated early with antibiotics may survive, although they often suffer permanent deformity due to partial or complete destruction of muscles ${ }^{1}$. The key to preventing losses due to these infections is a good immunization program ${ }^{8}$.The disease is a cause of severe financial loss to cattle raiser in many parts of the world. When the disease occurs within a space, several numbers of cattle are affected within a few days and mortality rate in BQ approaches $100 \%{ }^{3}$. In Bangladesh, about $0.04 \%$ cattle are affected and among them about $50.74 \% \operatorname{dies}^{9}$. The present study had been undertaken to investigate the distribution of black quarter (BQ) disease with

*Corresponding author:

Dr. Abdul Ahad, Associate Professor, Department of Microbiology, Chittagong Veterinary \& Animal Sciences University, Khulshi 4202, Chittagong, Bangladesh Tel (Office): (031) 659093, Ext 110; Cell: 01552 456759; E-mail: ahad@dsr.kvl.dk 
respect to age, sex and breed of cattle in different Unions of Upazilla Raozan in Chittagong and also to diagnose the septicaemia condition of BQ based on gross lesions and microscopic examination.

\section{Materials and Methods}

\section{Subjects}

The study was carried out at Upazilla Veterinary Hospital at Raozan in Chittagong during the period from June to August 2006. Information about the total animal population of that Upazilla was taken from recorded data preserved at Upazilla Veterinary Hospital under the Department of Livestock Service. During the period 25 cases of black quarter (BQ) in eight Unions were found and they were included in this study. The cases were selected according to presumptive diagnosis, e.g., clinical history and clinical sign and laboratory diagnosis.

\section{Scoring}

Animals were scored according to physical structure and nutritive conditions and were classified into two groups. Body condition score (BCS)-2: This is indication of moderate body condition of the animals. Animals having hip bone and spinous process of thoracic vertebrae are less prominent due to cover with flesh and less amount of fat are categorized into this group. Body condition score (BCS)-3: It indicates the good body condition of the animals. Here, the animals having the hip bone and spinous process of thoracic vertebra are covered with moderate amount of fat.

\section{Diagnostic procedure}

Diagnosis of BQ was done on the basis of clinical history, antemortem findings, post-mortem findings and laboratory examination of clinical specimens. In case of ante-mortem findings, lameness mainly in affected limb was found. Initially affected areas were swollen, hot and painful. Later stage swelling spread and characteristic crackling sound were produced when pressed with hand. Other signs were high fever $\left(104-106^{\circ} \mathrm{F}\right)$, depression, complete anorexia, reluctance to move was observed in affected animals. In case of post-mortem findings, typical bloated appearance of carcass were seen immediately after death, skin over swelling was dry and discoloured. On incision of affected side released frothy dark red blood.

In case of post-mortem findings, typical bloated appearance of carcass were seen immediate after death, laying one side with affected leg stuck out, skin over swelling were normal but in centre it was found dry gangrene. On incision the connective tissue under skin and between the muscles of swollen area was found to be infiltrated with discoloured serum and small gas bubbles and when affected muscles were cut open they were found dark red. A characteristic rancid butter odour emanates from the incised muscle. For confirmatory diagnosis by laboratory examination samples were collected from affected muscle.

\section{Microscopic examination}

Fluid was taken from affected tissue with needle puncture, smear was made in glass slide dried up in air and fixed with methyl alcohol, and Gram staining was done according to standard procedure. Microscopic examination was performed under light microscope to find out characteristic Gram-positive, rod shaped singly or small irregular clumps of organism. Blood was taken from jugular vein in $6 \mathrm{~h}$ interval from onset of clinical sign to detect sign of septicaemia. Collected sample was examined under light microscope making smear on glass slides and stained by Gram staining technique.

\section{Culture}

Blood collected after $12 \mathrm{~h}$ was streaked on the surface of blood agar plates and incubated in a McIntosh anaerobic jar for $72 \mathrm{~h}$ to observe the nature of growth of organism. A portion of colonial growth was also examined thoroughly under microscope.

\section{Data analysis}

Data were entered into the spread-sheet programme (Excel, Microsoft Co 2007) for data summary and statistical analysis. Descriptive analysis was done using statistical software STATA7. Measures of association and variation were further established by doing PHI significance, Mantel-Haenszel test for linear association. The results were expressed in frequency (\%), prevalence ration and odds ratio (OR).

\section{Results and Discussion}

Prevalence of black quarter (BQ) affecting cattle in different Unions is shown in Table 1. Binajuri Union registered the relatively higher prevalence $0.001 \%$, while Gohira Union had lower prevalence $0.00008 \%$. The magnitude of probability of having BQ was highest in Binajuri Union and when compared to Gohira Union, the probability of the frequency of $\mathrm{BQ}$ was 12.5 times higher in Binajuri and likely in Chickdair (5.25 times) and Raozan (3.25 times).

Table 1. Prevalence of black quarter (BQ) disease in cattle of different Unions of Raozan Upazilla

\begin{tabular}{lcccc}
\hline Union & $\begin{array}{c}\text { Total } \\
\text { population }\end{array}$ & $\begin{array}{c}\text { No. (\%) of } \\
\text { positive case }\end{array}$ & Prevalence & $\begin{array}{c}\text { Prevalence } \\
\text { ratio }\end{array}$ \\
\hline Binajuri & 2,000 & $2(8)$ & 0.001 & 12.5 \\
Chickdair & 7,000 & $3(12)$ & 0.00042 & 5.25 \\
Dabua & 18,000 & $4(16)$ & 0.00022 & 2.75 \\
East Gujra & 7,000 & $1(4)$ & 0.00014 & 1.75 \\
Gohira & 25,000 & $2(8)$ & 0.00008 & 1.00 \\
Haladia & 25,000 & $3(12)$ & 0.00012 & 1.50 \\
Kadalpur & 10,000 & $2(8)$ & 0.0002 & 2.50 \\
Raozan & 30,000 & $8(32)$ & 0.00026 & 3.25 \\
\hline
\end{tabular}

Frequency of BQ was higher among the cattle over 12 months of age (60\%) compared to the age of 12 months or less (40\%) (Table 2). It has been reported that although BQ has been found in cattle as young as 2 months old, most losses occur in cattle between 6 months and 2 years of age ${ }^{1}$. Among the four breed categories of cattle, frequency of BQ was more in Red Chittagong breed (44\%), while in indigenous breed the frequency was registered to be comparatively lower. In case of male animal the frequency of BQ was about $60 \%$ that was more than female animal (40\%). Most (92\%) of the animals with BQ showed with moderate body condition. 
Table 2. Frequency of black quarter (BQ) disease in cattle according to demographic variable

\begin{tabular}{lc}
\hline Variable & $\begin{array}{c}\text { Frequency, } \\
\text { No. (\%) }\end{array}$ \\
\hline Age & \\
$\quad$ Up to 12 months & $10(40)$ \\
$\quad$ Over 12 months & $15(60)$ \\
Breed & \\
$\quad$ Red Chittagong & $11(44)$ \\
$\quad$ Red Chittagong cross & $5(20)$ \\
$\quad$ Holstein Friesian cross & $5(20)$ \\
Indigenous breed & $4(16)$ \\
Sex & \\
$\quad$ Male & $15(60)$ \\
Female & $10(40)$ \\
Body condition score (BCS) & \\
BCS-2 & $23(92)$ \\
BCS-3 & $2(8)$ \\
\hline
\end{tabular}

Regarding clinical feature among the BQ suspected clinical cases, hind quarter affection was observed to be relatively higher (36\%) than the other body parts (Table 3). Mortality was very high (72\%).

Table 3. Frequency of clinical feature of black quarter (BQ) disease in affected animals $(n=25)$

\begin{tabular}{lc}
\hline Variable & $\begin{array}{c}\text { Frequency, } \\
\text { No. (\%) }\end{array}$ \\
\hline Body part affected & \\
Fore limb muscle & $6(24)$ \\
Hind limb muscle & $9(36)$ \\
Neck muscle & $4(16)$ \\
Backbone muscle & $6(24)$ \\
Fate of disease & \\
Alive & $7(28)$ \\
Death & $18(72)$ \\
\hline
\end{tabular}

Measures of association between severities of BQ affected cases and different exposure variables have been presented in Table 4 . The younger animal affected with BQ registered more mortality (52.63\%) than their older counter part (47.37\%). However, the difference was not statistically significant $(p=0.79)$. This might be due to not classifying the animal in age from 6 months to 2 years of age in one group and rest of animal in another group. The mortality rate was higher in Red Chittagong breed (36.84\%) when affected with BQ than other breed (21.05\%). This difference was not evident to be significant $(p=0.385)$. The severity was resisted higher among male animal (73.68\%) after affecting with BQ than female (26.32\%). The difference in severity between sex was not proved to be significant $(p=0.36)$. The difference of severity of BQ affected cases with nutritional status (BCS-2 versus BCS-3) was also not statistically significant ( $p=0.26)$. However, the body part area of affection evident to be significantly associated with the reason of death of animal. Animal having hind quarter affected registered comparatively high mortality $(47.37 \%)$ than any part of affected animal with BQ $(p<0.001 \%)$.
Table 4. Measures of association between severities of black quarter (BQ) affected cases and different exposure variable

\begin{tabular}{lcc}
\hline Variable & $\begin{array}{c}\text { BQ mortality } \\
(\%)\end{array}$ & $\chi^{2}$ value \\
\hline Age & 52.63 & 3.08 \\
$\quad$ Up to 12 months & 47.37 & \\
$\quad$ Over 12 months & & \\
Breed & 36.85 & 3.043 \\
$\quad$ Red Chittagong & 21.05 & \\
$\quad$ Red Chittagong cross & 21.05 & \\
$\quad$ Holstein Friesian cross & 21.05 & \\
Indigenous breed & & \\
Sex & 73.68 & 4.39 \\
$\quad$ Male & 26.32 & \\
$\quad$ Female & & \\
Body condition score (BCS) & 84.21 & 1.24 \\
$\quad$ BCS-2 & 15.79 & \\
$\quad$ BCS-3 & & \\
Body part affected & 26.32 & 17.40 \\
$\quad$ Fore limb muscle & 47.37 & \\
Hind limb muscle & 21.05 & \\
Neck muscle & 5.26 & \\
Backbone muscle & & \\
\hline
\end{tabular}

The strength of association between frequency and subsequent mortality with BQ and their demographic variable has been presented in Table 5. Age up to 12 months has probability and subsequent mortality 6.66 times more than animal over 12 months of age. Male showed tendency to occur BQ and subsequent mortality about 7 times more than female. Red Chittagong cattle had probability to occur BQ 2.85 times more than other breeds.

According to demographic variable, it was observed that Red Chittagong, age up to 12 months, male cattle with moderate body condition and thigh muscle of body, all these are susceptible factor for BQ.

Table 5. Measurement of strength of association

\begin{tabular}{lcc}
\hline Variable & $\begin{array}{c}\text { Odds ratio } \\
(\mathrm{OR})\end{array}$ & $\chi^{2}$ value \\
\hline Age & 6.66 & 2.96 \\
$\quad$ Up to 12 months & 1.00 & \\
$\quad$ Over 12 months & & \\
Breed & 2.85 & 0.83 \\
$\quad$ Red Chittagong & 1.00 & \\
$\quad$ Red Chittagong cross & 1.00 & \\
$\quad$ Holstein Friesian cross & 1.00 & \\
Indigenous breed & & \\
Sex & 7.00 & \\
$\quad$ Male & 1.00 & \\
$\quad$ Female & & \\
\hline
\end{tabular}


After $6 \mathrm{~h}$ of appearing of clinical sign, no bacteria were found in blood smear. After $12 \mathrm{~h}$, bacteria were found in blood and indicate initiation of septicaemia. After $12 \mathrm{~h}$ and before the death of animal, bacteria were found circulated, which revealed that septicaemia persisted up to fatal outcome. At later stage of septicaemia, characteristic BQ lesion were found developed in different areas like muscles in shoulder region and over backbone. In the present observation, it was observed that the animals treated within $12 \mathrm{~h}$ of onset of clinical signs responded well. However those animals have been treated after later stages succumbed to death ${ }^{9}$. It is a common fashion in this country that BQ is treated by application of antibiotic. High dose of antibiotics is choice of treatment in early case (before $12 \mathrm{~h}$ ), but after $12 \mathrm{~h}$ if animal remain alive, antibiotics with specific antitoxin can be chosen as specific therapeutic means. But black quarter antiserum is not available in Bangladesh. Therefore, the better option to control the disease would be getting the animal vaccinated against black quarter.

\section{References}

1. Robson S. 2007. Blackleg in cattle. Available at: http:// www.thedairysite.com/articles/843/blackleg-in-cattle. Accessed 22 August 2007.
2. Blood DC \& Henderson JA. 1968. Disease caused by bacteria-II. Veterinary Medicine, $3^{\text {rd }}$ edn, pp 325-327. Williams \& Wilkins Co, Baltimore, Maryland.

3. Samad MA. 2001. Bacterial disease. Animal Husbandry and Medicine, $2^{\text {nd }}$ edn, pp 599-601. LEP Publication, Dhaka.

4. Awad FI, Gadalla MS \& Farrag I. 1973. Studies on the aetiology of black quarter in Egyptian cattle. Egyptian J Vet Sci. 10: 45-51.

5. Merchant IA, Packer RA. 1983. The genus Clostridium. Veterinary Bacteriology and Virology, $7^{\text {th }}$ edn, pp 389-402. CBS Publisher \& Distributor, New Delhi.

6. Noble J. 2007. Cattle diseases: Blackleg. Available at: http:// www2.dpi.qld.gov.au/beef/3450.html. Accessed 22 August 2007.

7. Chakraborti A. 2000. Black quarter. A Textbook of Preventive Veterinary Medicine, pp 375-381. Kalyani Publishers, New Delhi.

8. Awad FI, Farrag I, Hussein AZ, et al. 1986. The immunizing power of three blackleg vaccines. Assiut Vet Med J. 17: 201-211.

9. Udall DH. 1972. Acute bacterial disease. The Practice of Veterinary Medicine, $6^{\text {th }}$ edn, pp 430-435. Oxford \& IBH Publishing Co Pvt Ltd, Andra Pradesh. 